\title{
Obstacles and alternative options for cardiac rehabilitation in Nanjing, China: an exploratory study
}

Hong Jin ${ }^{*+}$, Qin Wei, Long Chen, Qin Sun, Yun Zhang, Juan Wu, Genshan Ma and Naifeng Liu* ${ }^{*+}$

\begin{abstract}
Background: Coronary heart disease (CHD) is a major cause of morbidity and mortality, and cardiac rehabilitation $(C R)$ is still not well developed in mainland China. The objective of this study is to investigate the barriers associated with those seeking cardiac rehabilitation (CR) and to explore appropriate secondary prevention modalities tailored to the needs of Chinese patients with coronary heart disease (CHD).

Methods: A consecutive series of eligible patients was recruited from the cardiac department of a teaching hospital in Nanjing, located in southeast China. Structured face-to-face interviews were conducted with 328 patients prior to hospital discharge. Patient preferences for seeking an outpatient CR program or an alternative outpatient self-choice, minimal-cost educational program were evaluated. Socio-demographic characteristics and clinical data were assessed. Additionally, patients were asked to provide the reasons affecting their choice.
\end{abstract}

Results: Overall, only $14.3 \%$ patients preferred the standard CR program. Factors associated with non-participating were female gender (odds ratios [ORs], 6.05, 95\% Cl, 1.30-28.19), older age (ORs, 1.11, 95\% Cl, 1.04-1.19, per year), less education (ORs, 8.13, 95\% Cl, 2.83-23.38), low income (ORs, 3.26, 95\% Cl, 1.24-8.54), and having either basic medical care or a lack of health insurance (ORs, 10.01, 95\% Cl, 3.90-25.68). The most common reason for refusing to participate in CR was that patients could not afford it. Of the remaining patients, $65.8 \%$ patients chose self-choice educational programs, especially for female (ORs, 5.84, 95\% Cl, 2.67-12.79), older (ORs, 1.06, 95\% Cl, 1.02-1.11, per year), and low income (ORs, $2.14,95 \% \mathrm{Cl}, 1.12-4.10)$ patients. The main reasons for their preferences were their desires for more information about disease and risk factors, the low cost, feasibility, and saving time.

Conclusions: Multiple barriers, which may occur at the patient, health system, and societal levels, have prevented eligible patients from participating in CR programs. Self-choice educational programs, an alternative model incorporating more information, would strongly meet the needs of most patients. A feasible delivery format for secondary prevention should be provided for all CHD patients.

Keywords: Coronary heart disease, Secondary prevention, Cardiac rehabilitation, Health education

\section{Background}

Coronary heart disease (CHD) is a major cause of morbidity and mortality in China, despite advances in medical treatment [1-3]. Urbanization, industrialization, and the aging of the population have resulted in a rapid and significant increase in the prevalence and incidence of CHD in the past decades [1]. Uncontrolled risk factors,

\footnotetext{
*Correspondence: jinhong5985@163.com; liunf2006@126.com

${ }^{\dagger}$ Equal contributors

Department of Cardiology, Zhongda Hospital, Medical School of Southeast University, 210009 Nanjing, Jiangsu, China
}

unhealthy lifestyles, and lack of knowledge about the disease have resulted in poor management of CHD among Chinese patients $[4,5]$.

The high mortality and morbidity associated with CHD has resulted in calls for the universal provision of rehabilitative and preventive measures for all patients with this disease [6]. During the past decades, many studies conducted in Western countries have demonstrated that cardiac rehabilitation (CR) can significantly reduce cardiac risk and symptoms, improve functional capacity, enhance psychological well-being and reduce 
the risk of further cardiac events [7-9]. However, even in many developed countries, participation rate in hospitalbased CR programs are reported to be low, particularly for women $[10,11]$, the elderly $[12,13]$, patients at a lower socioeconomic status [14], patients with less education [15] and patients lacking insurance [16]. Many attempts have been made by rehabilitation centers to offer choices in the format of the program, in an effort to encourage participation. These alternatives have included individual consultations with health professionals and self-education [17], as well as modular approaches [18], group counseling programs [19], and home-based CR programs [20]. Randomized trials studying the effects of these alternative CR models have demonstrated beneficial outcomes for patients participating in such programs after cardiac events [18-20].

In developed Western countries, CR is a rapidly developing area on health care. However, in mainland China, the concept of $\mathrm{CR}$ is relatively new and has received little attention [21]. In contrast to the high numbers of emergency percutaneous coronary intervention (PCI) performed, CR is still in its infancy, and CR services are rarely found in most parts of the country [5]. This fact is surprising, considering the size of the country and its population. A lack of priority, limited health care resources and scarce rehabilitation facilities are believed to pose major challenges to the development and implementation of CR programs in mainland China [5]. To date, there is no standard design for CR programs in mainland China. In searching for barriers to $\mathrm{CR}$ and potential solutions to the CR gap, we firstly introduced a standard CR model based on a 3-month outpatient program for patients following acute coronary syndrome (ACS) [22] in our center. Secondly, if patients did not agree to participate in the standard CR program, we offered an alternative self-choice educational program for increasing knowledge about heart disease and stimulating lifestyle changes.

Therefore, the aims of this study were: 1) to identify factors and reasons for non-participating in the standard CR program; 2) to investigate whether patients preferred an alternative self-choice educational program model for getting information; 3 ) to further evaluate predictors for attending the alternative self-choice educational program. Finally, 4) the desire for specific information regarding heart disease and preventive therapies were also examined.

\section{Methods}

\section{Patient population}

A consecutive series of patients with ACS between September 2010 and March 2012 were recruited from a cardiac center of teaching hospital with approximately 1500 beds, located in Nanjing, a provincial capital with 9 million populations. Patients were excluded if they met any of the following criteria: were over 80 years of age or had severe comorbidities, psychiatric illness or cognitive decline that impaired their ability to complete the study's measures. A total of 468 patients were admitted to the hospital for ACS during the study period. After excluding patients based on the criteria above, there were 372 eligible patients who initially consented to participate in the study. However, 31 patients failed to follow up, and 13 patients were unable to complete interview, leaving a population of 328 patients (Figure 1). All participants gave full written informed consent, and the study was approved by the Committee of Clinical Investigation of Southeast University School of Medicine.

Data collected from the medical records included demographic information, clinical history of chronic diseases, comorbidities, cardiac diagnoses (ST segment elevated myocardial infarction (STEMI), non-ST segment elevated myocardial infarction (NSTEMI), and unstable angina), medications, and record of whether invasive procedures were performed during hospitalization ( $\mathrm{PCI}$, or coronary artery bypass graft (CABG)).

\section{Design}

While patients were still in the hospital following their PCI, CABG, or continued medical treatment procedure, they were approached by a nurse from the CR team to check for eligibility and for recruitment in the study. After the acute care period, all patients were approached by a nurse from the $C R$ team regarding participation in a standard outpatient CR course. The proposed outpatient CR program was a 12 weeks plan that included moderate intensity endurance training and education about the disease and risk factors. The endurance training

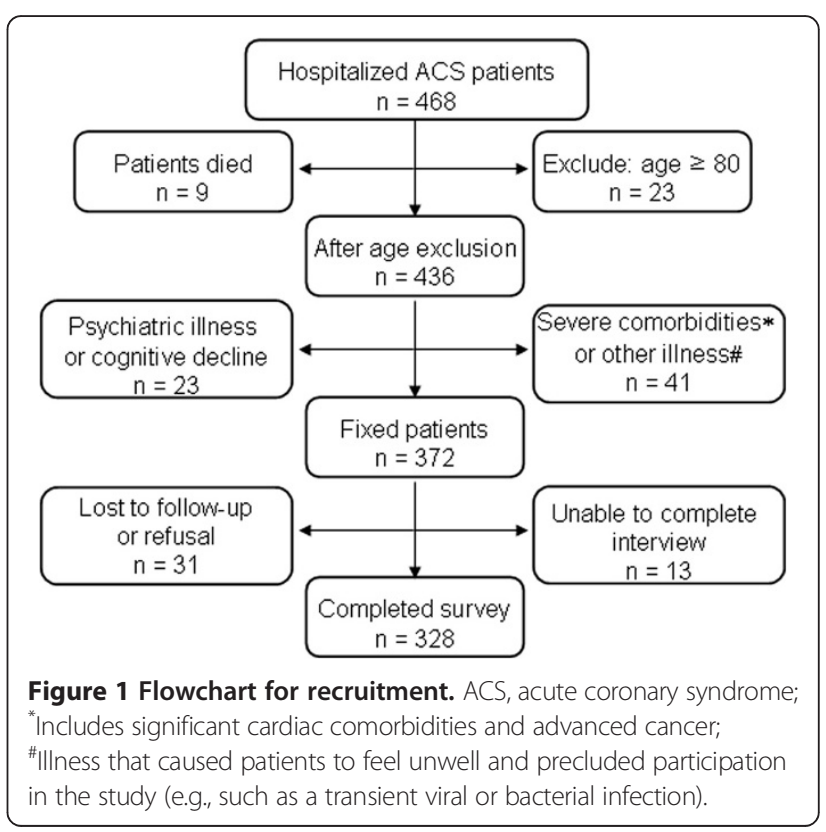


was administered for 45 minutes per day for 3 times a week at a target aerobic intensity of $50 \%$ to $70 \%$ heart rate reserve. In addition, all exercise training group patients received individual counseling on exercise prescription, secondary prevention, and daily activities by a physician and a nurse over a period of 12 weeks. Patients would need to pay for the CR program at their own expense because basic medical insurance did not cover the costs of the program. If patients declined to attend the standard CR program, they were offered an alternative format of education regarding secondary prevention-a self-choice, minimal cost educational program, which was promoted by local enthusiasts (e.g., cardiologists (H.J.), nurses (Q.S.) or physiotherapists (Y.Z.)) who perceived a therapeutic gap and filled it, often by "borrowing" time from other professions required for this multidisciplinary activity. Patients were encouraged to attend education classes, which were held once weekly with lectures given by physicians, nurses, dieticians, and pharmacists on cardiac disease, secondary prevention, management, diet, smoking cessation, and medication.

Face-to-face interviews were conducted with $372 \mathrm{pa}-$ tients prior to hospital discharge. These interviews were approximately 20 minutes and were administered in a location convenient to the patient (e.g., bedside). Of the 372 patients who were interviewed at baseline (i.e., prior to discharge), complete data regarding all secondary prevention format preferences were available in 328 cases. The data regarding patient' attitudes and beliefs about CR programs, as well as their preference for a self-choice educational program, were collected using a structured questionnaire. Researchers were registered nurses with graduate degrees and specialized expertise in cardiac care.

Participants completed both the face-to-face interviews and the structured questionnaire independently prior to discharge. The questionnaire surveyed the following: the first section included patient baseline characteristics such as age, gender, marital status, educational level, employment status, health insurance status, and income bracket prior to the acute event. The second section included attitudes about participation in a standard CR program. First, the researchers advised patients about the purposes, benefits, and costs associated with the CR program. Then, patients were asked if they would like to participate in a CR program. All patients responded 'Yes' or 'No'. Patients who did not want to attend were asked about their reasons. To perform this assessment, they were asked, "Why did you decline to join the CR program?' Patients were prompted with possible options, which included unaffordability, transportation issues, work or time conflicts, health problems, self-exercise (their desire to exercise independently of the program), skepticism towards the benefits of rehabilitation, and lack of family support, among others and were asked to choose their reasons.

The third section was explored within the group who did not agree to join a CR program. Patients were asked if they would like to attend a self-choice educational program to obtain more information about heart disease and lifestyle. Among patients who agreed to attend a self-choice educational program, we further assessed the reasons for joining the educational program, such as receiving more information about disease and risk factors, low cost, feasibility, saving time, among others. Additionally, these patients were asked to choose the specific information they desired, namely, knowledge about the disease, physical activity, diet, medication, stress management, modifying risk factors, career advice, and lifestyle changes, among others.

Additionally, before hospital discharge, all study patients were asked to complete a questionnaire, the Chinese Mandarin versions of the Short Form 36-Item (SF-36) Health Survey [23], which was used to assess the health status. The SF-36 is a widely used generic instrument consisting of 36 items. It yields 8 subscale profiles, including physical and mental health summary measurements. A high score reflects good health status. After 12 weeks from hospital discharge, SF-36 questionnaires were repeated in all study patients, including those who did not participate in CR or self-choice educational program.

Attendance at standard CR or a self-choice educational program was confirmed by a telephone survey 3 months after the initial interview, with attendance defined as having attended at least one CR or self-choice educational program session.

\section{Statistical analysis}

Patients were divided into three groups according to whether they agreed to attend the CR program, the selfchoice educational program, or refused to attend both programs. All data are expressed as the means \pm standard deviations for normally distributed data and as the medians (interquartile range) for skewed continuous variables. Comparisons of continuous variables among the three groups were performed using a one way analysis of variance (ANOVA) or Kruskal-Wallis test. The Chi-square test was used to compare categorical variables across groups. A multivariable logistic regression analysis was performed to indentify factors associated with non-participating in $\mathrm{CR}$, defined as refusal to participate in CR prior to hospital discharge, or attendance in a self-choice educational program. Significant univariate predictors were included in multivariate logistic regression analyses. We included 5 covariates in the model: age, gender, education, insurance, and income. Statistical analyses were performed using SPSS software 16.0 (SPSS Inc., Chicago, USA). All tests were two- 
sided, and a p-value of less than 0.05 was considered significant.

\section{Results}

Overall, the mean age of the cohort was $63.0 \pm 7.6$ years, and $26.2 \%$ were women. A comparison of the socioeconomic and clinical characteristics of patients among three groups is shown in Table 1.

When compared to patients who did not agree to participate in $\mathrm{CR}$, those who preferred $\mathrm{CR}$ were younger and more likely to be male $(\mathrm{p}<0.001)$. Low income and less educated patients were more likely to prefer the educational program compared to the patients who declined the $C R$ or educational programs $(\mathrm{p}<0.001)$.
Patients with basic medical care or without health insurance were less likely to prefer $\mathrm{CR}$ as compared to those who agreed to participate in a CR program $(\mathrm{p}<0.001)$. There were no differences across groups in terms of BMI, medical diagnosis, number of diseased vessels, management strategies (PCI, CABG, or continued medical treatment), length of hospital stay, or ejection fraction as evaluated by echocardiography. In the multivariable model, factors that were independently associated with non-participation in CR included female gender, older age, basic medical care or lack of insurance, low income, and poor education (Table 2).

Reasons given by patients who refused to participate in a CR program are presented in Table 3. Patients were

Table 1 Baseline characteristics of study patients

\begin{tabular}{|c|c|c|c|c|}
\hline \multirow[t]{2}{*}{ Characteristics } & \multicolumn{2}{|c|}{ Refusal to attend CR $(n=281)$} & \multirow{2}{*}{$\begin{array}{c}\text { Agreed to } \\
\text { attend CR } \\
(n=47)\end{array}$} & \multirow[t]{2}{*}{$\mathrm{p}$ value } \\
\hline & Agree to attend EP $(n=185)$ & Refusal to attend EP $(n=96)$ & & \\
\hline Age, years & $65.5 \pm 6.4$ & $61.3 \pm 8.3$ & $56.7 \pm 5.6$ & $<0.001$ \\
\hline Gender, female & $75(40.5)$ & $9(9.4)$ & $2(4.3)$ & $<0.001$ \\
\hline Married & $181(97.8)$ & $94(97.9)$ & $44(93.6)$ & 0.256 \\
\hline Education: Junior high school or lower & $125(67.6)$ & $59(61.5)$ & $5(10.6)$ & $<0.001$ \\
\hline Employed & $92(49.7)$ & $50(52.1)$ & $29(61.7)$ & 0.341 \\
\hline Current smoker & $71(38.4)$ & $38(39.6)$ & $20(42.6)$ & 0.870 \\
\hline \multicolumn{5}{|l|}{ Health insurance status } \\
\hline Basic medical care or lack of health insurance & $128(69.2)$ & $68(70.8)$ & $8(17.0)$ & \multirow[t]{2}{*}{$<0.001$} \\
\hline Free medical care or other commercial health insurance & $59(31.9)$ & $26(27.1)$ & $39(83.0)$ & \\
\hline \multicolumn{5}{|l|}{ Income: (Chinese Yuan/month) } \\
\hline $\operatorname{Low}(\leq 3,000)$ & $103(55.7)$ & $26(27.1)$ & $9(19.1)$ & \multirow[t]{3}{*}{$<0.001$} \\
\hline Medium $(3,000-5,000)$ & $62(33.5)$ & $47(49.0)$ & $10(21.3)$ & \\
\hline High $(\geq 5,000)$ & $20(10.8)$ & $23(24.0)$ & $28(59.6)$ & \\
\hline $\mathrm{BMI}\left(\mathrm{kg} / \mathrm{m}^{2}\right)$ & $24.3 \pm 2.4$ & $24.2 \pm 2.3$ & $23.8 \pm 2.1$ & 0.443 \\
\hline \multicolumn{5}{|l|}{ Medical diagnosis: } \\
\hline STEMI & $65(35.1)$ & $35(36.5)$ & $22(46.8)$ & \multirow[t]{3}{*}{0.534} \\
\hline NSTEMI & $71(38.4)$ & $35(36.5)$ & $12(25.5)$ & \\
\hline Unstable angina & $49(26.5)$ & $26(27.1)$ & $13(27.7)$ & \\
\hline No. of diseased vessels & $1(1-2)$ & $1(1-2)$ & $1(1-2)$ & 0.847 \\
\hline $\mathrm{EF}$ & $50(45-55)$ & $50(45-55)$ & $50(45-57)$ & 0.740 \\
\hline \multicolumn{5}{|l|}{ Management strategies } \\
\hline $\mathrm{PCl}$ & $163(88.1)$ & $86(89.6)$ & $37(78.7)$ & 0.161 \\
\hline CABG & $9(4.9)$ & $4(4.2)$ & $5(10.6)$ & 0.239 \\
\hline Duration of hospitalization (days) & $6(5-7)$ & $6(5-7)$ & $6(5-8)$ & 0.351 \\
\hline Previous heart disease & $51(27.6)$ & $21(21.9)$ & $16(34.0)$ & 0.287 \\
\hline \multicolumn{5}{|l|}{ Co-morbidity: } \\
\hline Diabetes & $60(32.4)$ & $22(22.9)$ & $15(31.9)$ & 0.235 \\
\hline Hypertension & $87(47.0)$ & $34(35.4)$ & $24(51.1)$ & 0.105 \\
\hline
\end{tabular}


Table 2 Multivariate logistic regression model for factors associated with non-participating in cardiac rehabilitation (CR) $(\mathbf{n}=328)$

\begin{tabular}{|c|c|c|c|}
\hline & Adjusted ORs & 95\% CI Lower - Upper & $\mathrm{p}$ value \\
\hline Age (per year) & 1.11 & $1.04-1.19$ & 0.002 \\
\hline \multicolumn{4}{|l|}{ Gender } \\
\hline Male & 1.00 & Reference group & \\
\hline Female & 6.05 & $1.30-28.19$ & 0.022 \\
\hline \multicolumn{4}{|l|}{ Education } \\
\hline$>$ Junior high school & 1.00 & Reference group & \\
\hline$\leq$ Junior high school & 8.13 & $2.83-23.38$ & $<0.001$ \\
\hline \multicolumn{4}{|l|}{ Health Insurance } \\
\hline Free or commercial & 1.00 & Reference group & \\
\hline Basic medical care or none & 10.01 & $3.90-25.68$ & $<0.001$ \\
\hline \multicolumn{4}{|l|}{ Income (Chinese Yuan/month) } \\
\hline Medium/high $(>3,000)$ & 1.00 & Reference group & \\
\hline Low-income $(\leq 3,000)$ & 3.26 & $1.24-8.54$ & 0.016 \\
\hline
\end{tabular}

asked to indicate the most important reason. The most common reason for refusing to attend CR was unaffordability. Other reasons included conflicts with work or insufficient time to attend, poor health (chronic dialysis, peripheral vascular disease, trait anxiety, depression, chronic obstructive pulmonary disease, stroke, arthritis, and other disability/impairment), transportation problems, and lack of support from family members.

Among patients who declined to participate in the CR program, 185 patients $(65.8 \%)$ preferred an alternative educational program. The multiple regression analysis of predictors for the participation in the educational program is summarized in Table 4. Female, older, and low-income patients were more likely to attend the educational program. Unlike predictors for the participation in CR, insurance status and education level was not associated with participation rates in the alternative educational program.

\section{Table 3 Reasons for patients' refusal to participate in} cardiac rehabilitation (CR)

\begin{tabular}{lc}
\hline Reason* & $\begin{array}{c}\text { Patients ( } \mathbf{n = 2 8 1 )} \\
\mathbf{n ~ ( \% ) ~}\end{array}$ \\
\hline Unaffordability (Cannot afford CR) & $172(61.2)$ \\
Work or time conflicts & $43(15.3)$ \\
Difficulty with commute to rehabilitation center & $22(7.8)$ \\
Health problems & $15(5.3)$ \\
Self-exercise & $12(4.3)$ \\
Family members did not support CR & $11(3.9)$ \\
Others & $6(2.1)$ \\
$\quad$ Considered CR to be non-essential or reluctant & 4 \\
to join & 2 \\
Responsibility to domestic duties & \\
\hline
\end{tabular}

*Patients could give only one reason.
When patients were asked why they preferred the selfchoice educational program over $\mathrm{CR}$, they gave the reasons as listed in Figure 2. The foremost reason was their desire to learn about the disease and how to reduce risk factors. Low costs were considered the second most important reason for their decision. Other reasons were its feasibility and time-saving nature.

Lastly, patients were asked what they wanted to learn from health professionals (Table 5). The majority of patients wanted to know how to exercise, manage risk factors, and gain knowledge about diseases, diet, and pharmacotherapy. Lifestyle changes and career advice were considered important information in less than half of the study patients. In addition, a minority of patients reported that they needed advice on strategies for coping with stress and depressed mood.

There was no significant difference in scores of physical function and mental health among three groups at baseline. After 12 weeks from hospital discharge, there was an improvement in scores of physical function and mental health, with an increase of $79.7 \%$ and $58.6 \%$ in CR group, $27.6 \%$ and $22.4 \%$ in educational program group, and $18.8 \%$ and $11.2 \%$ in patients who did not participate in CR or educational program. These results showed that $\mathrm{CR}$ and self-choice educational program had a profound effect on physical function and mental health (Table 6, $\mathrm{p}<0.001$ ).

\section{Discussion}

Of the eligible patients who were offered a standard CR program, only a low proportion of patients chose this option. It is evident that there are many factors leading to poor participation rates for CR. Insurance coverage has been shown to be a major factor impacting participation in 
Table 4 Multivariate logistic regression model for factors associated with participation in self-choice educational program $(\mathbf{n}=\mathbf{2 8 1})$

\begin{tabular}{|c|c|c|c|}
\hline & Adjusted ORs & 95\% CI Lower - Upper & $\mathrm{p}$ value \\
\hline Age (per year) & 1.06 & $1.02-1.11$ & 0.004 \\
\hline \multicolumn{4}{|l|}{ Gender } \\
\hline Male & 1.00 & Reference group & \\
\hline Female & 5.84 & $2.67-12.79$ & $<0.001$ \\
\hline \multicolumn{4}{|l|}{ Education } \\
\hline$>$ Junior high school & 1.00 & Reference group & \\
\hline$\leq$ Junior high school & 1.18 & $0.63-2.21$ & 0.606 \\
\hline \multicolumn{4}{|l|}{ Health Insurance } \\
\hline Free or commercial & 1.00 & Reference group & \\
\hline Basic medical care or none & 1.06 & $0.57-1.97$ & 0.850 \\
\hline \multicolumn{4}{|l|}{ Income (Chinese Yuan/month) } \\
\hline Medium/high $(>3,000)$ & 1.00 & Reference group & \\
\hline Low-income $(\leq 3,000)$ & 2.14 & $1.12-4.10$ & 0.022 \\
\hline
\end{tabular}

CR $[11,24]$. Patients without insurance are less likely to participate, which agrees with previous studies that report a lack of funding from insurance or other sources to impact attendance $[16,24]$. In agreement with this, very few people have free medical care or other commercial health insurance in mainland China [25]. Although the majority of the population are covered by the National Health Service in mainland China, the proportion of people who receive reimbursement for their medical treatment fees among those with medical insurance varies significantly by the type of medical insurance [25]. Moreover, the treatment costs for most patients are only partially reimbursed through basic medical care when they become ill and are admitted to the hospital. The average proportion of medical payments paid out-of-pocket is approximately $60 \%$ for the whole population, and government expenditures for health account for only $36 \%$ of the total health expenditure $[4,26]$. In addition, according to the reimbursement system, the National Health Service is unlikely to pay for a patient's participation in a CR program after hospital discharge [5]. This further leads to a financial burden for most patients.

Socioeconomic status also reflects financial and material well-being, factors that may contribute to participation in CR. Similar to findings in industrialized countries $[14,27,28]$, patients with higher income and education were more likely to attend CR. Given the association between cost and insurance coverage, lower educational and economic status may serve as markers for lack of insurance. In addition, patient characteristics such as age and gender have been reported to be significant predictors of participation in CR. In agreement with previous studies $[10,12,13]$, older patients and women were less likely to attend CR. The reason for this disparity may be related to patients' preferences, but it is even more likely that gaps in CR participation for these groups are due to

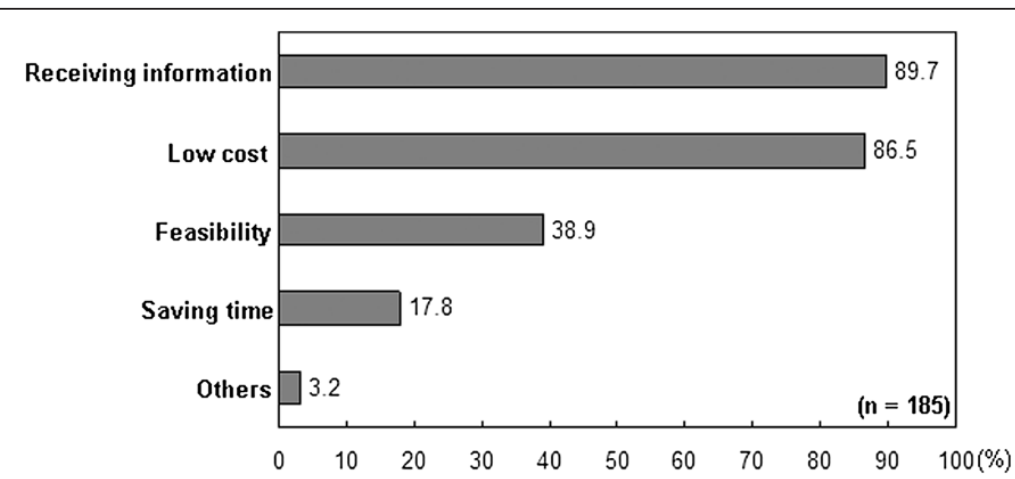

Figure 2 Reasons for choosing self-choice educational program. Bars represent the percentage of patients who provided the indicated answer. Patients could choose more than one answer. 


\begin{tabular}{|c|c|}
\hline Relevant information* & Patients $(n=185), n(\%)$ \\
\hline Exercise & $145(78.4)$ \\
\hline Modifying risk factors & $127(68.6)$ \\
\hline Knowledge about the disease & $119(64.3)$ \\
\hline Symptom management & $107(57.8)$ \\
\hline Nutritional counseling & $105(56.8)$ \\
\hline Pharmacotherapy & $98(53.0)$ \\
\hline Lifestyle changes & $72(38.9)$ \\
\hline Career advice and returning to work & $60(32.4)$ \\
\hline Management of depressed mood & $45(24.3)$ \\
\hline Stress management & $34(18.4)$ \\
\hline
\end{tabular}

*Patients could give more than one choice.

financial strains, self-exercise, time conflicts, transportation problems, or a lack of family support. The most common reason for patients' refusal to attend CR was that patients could not afford CR, which may be attributed to perceived insufficient health care resources and an under-developed reimbursement system. Understanding patient-reported reasons for their decision may further help understand the barriers associated with CR participation. Thus, a lack of emphasis, resources, and institutional support for such services are a few of the most important obstacles preventing greater participation in CR programs in mainland China.

The majority of patients in our study showed a clear preference for choosing the $\mathrm{CR}$ alternative, a self-choice educational program offered at minimal cost. Patients provided a wide range of reasons for their choices. Of these, receiving more information, the low cost, feasibility, and saving time were the most frequently given advantages of the self-choice educational programs. The strong desire for information among patients after acute cardiac events agrees with previous reports [29], and this indicates that the amount of information received during hospital stays are low. During a patient's stay in the acute care, it is unlikely that physicians and nurses provide effective education about lifestyle modifications due to the short duration of the hospital stay as well as the high physical and emotional stress experienced by the patient during this phase of hospitalization. Additionally, because infor- mation may have been delivered at a time, patients were unable to completely understand some information by medical staffs and the need for information increases when patients are left on their own to handle their problems [30]. In this situation, the availability of selfchoice educational programs at low cost, preferred by the majority of patients due to its affordability and feasibility, is a better opportunity to provide information about their disease, educate them about compliance with treatment regimens, and make informed decisions about lifestyle changes.

Women were more likely to prefer educational programs. Heart disease in women is characterized by a poorer prognosis, greater disability, and a higher rate of morbidity and early death after myocardial infarction compared with men [31]. Women often underestimate their risk for heart disease $[32,33]$ and have longer pre-hospital delays than men [34]. After an acute cardiac event, women did not feel that they had received enough information from a health professional about treatment and preventive health behaviors and wanted a great deal of information about the management of their disease [29]. In accordance with a previous study [35], older patients wanted more information on disease management and prevention than younger and employed patients. The following explanations of these results are possible: 1) older age is associated with receiving less information during hospitalization [30]; 2) older patients may need information repeated due to age-related visual and hearing problems. In addition, lower-income patients wanted to attend educational programs, which was in line with recent evidence that low-socioeconomic status participants showed similar attendance and adherence to program guidelines as their higher-socioeconomic status counterparts [36].

The findings from this study will have significant implications for those seeking options for the management of CHD, particular for disadvantaged people with inadequate medical resources. Educational programs, as a simple and effective alternative, could provide sufficient information about the disease process and health promotion, disease prevention and risk education to those patients who are not able to access standard CR. However, a single education intervention seems to be insufficient as a means to obtain sustainable and meaningful benefits [37]. Thus, it should be emphasized that, wherever possible, standard CR should be used as part of the outpatient

Table 6 Percent changes in scores of SF-36 Questionnaire after 12 weeks from hospital discharge in all study patients

\begin{tabular}{|c|c|c|c|c|}
\hline \multirow[t]{2}{*}{ Variables } & \multicolumn{2}{|c|}{ Refusal to attend CR $(n=281)$} & \multirow{2}{*}{$\begin{array}{c}\text { Agreed to } \\
\text { attend CR }(n=47)\end{array}$} & \multirow[t]{2}{*}{$\mathrm{p}$ value } \\
\hline & Agree to attend EP $(n=185)$ & Refusal to attend EP $(n=96)$ & & \\
\hline Physical function, \% & $27.6(18.2-41.4)$ & $13.8(6.0-26.8)$ & $79.7(58.5-108.7)$ & $<0.001$ \\
\hline Mental health, \% & $22.4(11.1-44.5)$ & $11.2(5.2-25.0)$ & $58.6(41.5-125.2)$ & $<0.001$ \\
\hline
\end{tabular}

Data are represented as the median (interquartile); SF-36, Short Form 36-Item Health Survey; CR, cardiac rehabilitation; EP, educational program; P value represents statistical difference among three groups. 
treatment plan following cardiac events based on evidencebased guidelines [38].

Despite the effectiveness of conventional centre-based CR programs, participation rates are low $[15,39]$ and the majority of patients requiring $\mathrm{CR}$ are missing out on evidence-based health benefits of lifestyle interventions. Little research has been conducted on improving health outcomes for the majority of cardiac patients who do not attend CR. This study addresses these gaps in public health practice by testing an alternative delivery mode for CR. While this study leads to conclusions specific to mainland China, it has implications for other countries as well. More research is needed to explore possible strategies to overcome these barriers to participation in CR.

\section{Limitations}

Our study has several limitations, particularly with regards to how we measured CR or self-choice educational program attendance. Attendance at CR or self-choice educational program was defined as having attended at least one session. We did not differentiate between patients who completed all sessions and patients who only ever attended one session. This precluded investigations associating between patient preferences and non-completion of the $\mathrm{CR}$ or self-choice educational program. The National Service Framework set the target at $85 \%$ for the number of eligible patients invited to join rehabilitation programs [40]. This study reports only on the numbers participating in rehabilitation programs, so it can only indirectly reflect the failure to meet this target. Although participation rate probably included a few who joined the program but dropped out too soon to gain the real benefit, the one of goals of this study were to examine the obstacles to CR and patient' wishes to attend alternative secondary preventive measures. In fact, only few patients dropped out of CR (2.1\%) or of self-choice educational programs (3.8\%) according latest data. The second main limitation pertains to measurement. Although the validity of questionnaire regarding preferences for $\mathrm{CR}$ or a self-choice educational program was not verified, the potential for social desirability biases in participant responses could be ruled out. Patients were asked about their preferences and reasons for their decisions prior to discharge. This enabled the exploration of patient preferences at a time when patients were likely to be making decisions about their own secondary preventive measures.

There were also other limitations. First, our study only considered a sample from one localized geographical location. Thus, it may not be possible to generalize our results to those living in other regions of China. Secondly, we had a relatively small study population, and our participants were recruited from a single center with a stable population. Finally, there is a lack of long-term follow-up data. We are not able to assess the extent to which participation in either secondary prevention program sponsored by our center affected the prognosis of these patients.

\section{Conclusions}

There were many barriers at the levels of the patient, the health system, and society that prevented eligible patients from accessing CR services. It is essential to provide a flexible model for CR delivery that is suitable for local conditions and meets the needs of patients. The majority of patients expressed a strong desire for self-choice educational programs to obtain more information about disease and health promotion even after hospital discharge, especially among female, older, and low-income patients. Findings from this study may be used to guide health professionals in providing or offering effective, safe, convenient and culturally relevant programs for CHD secondary prevention.

\section{Abbreviations}

CHD: Coronary heart disease; CR: cardiac rehabilitation; PCI: Percutaneous coronary intervention; ACS: Acute coronary syndrome; STEMI: ST segment elevated myocardial infarction; NSTEMI: Non-ST segment elevated myocardial infarction; CABG: Coronary artery bypass graft; ANOVA: One way analysis of variance; SF-36: Short form 36-item health survey.

\section{Competing interest}

The authors declare that they have no competing interest.

\section{Authors' contributions}

HJ was the principal investigator, involved in designing the study, analyzing the data, and writing the manuscript. QW and LC contributed to data collecting. $\mathrm{HJ}$, QS, YZ and JW were responsible for exercise training and educational programs. NFL and GSM provided expertise in the research design and plan coordination. All authors read and approved the final manuscript.

\section{Acknowledgments}

This study was supported by the Science and Technology Support Social Development Research Fund, a division of the Health Bureau of Jiangsu Province Government (grant no. BE2011793).

Received: 22 October 2013 Accepted: 12 February 2014 Published: 17 February 2014

\section{References}

1. Zhang XH, Lu ZL, Liu L: Coronary heart disease in China. Heart 2008, 94(9):1126-1131.

2. Critchley J, Liu J, Zhao D, Wei W, Capewell S: Explaining the increase in coronary heart disease mortality in Beijing between 1984 and 1999. Circulation 2004, 110(10):1236-1244.

3. Zhao D, Liu J, Wang W, Zeng Z, Cheng J, Liu J, Sun J, Wu Z: Epidemiological transition of stroke in China: twenty-one-year observational study from the Sino-MONICA-Beijing project. Stroke 2008, 39(6):1668-1674.

4. Niu S, Zhao D, Zhu J, Liu J, Liu Q, Liu J, Wang W, Smith SC Jr: The association between socioeconomic status of high-risk patients with coronary heart disease and the treatment rates of evidence-based medicine for coronary heart disease secondary prevention in China: results from the Bridging the Gap on CHD Secondary Prevention in China (BRIG) Project. Am Heart J 2009, 157(4):709-715. e1.

5. Wang W, Chair SY, Thompson DR, Twinn SF: Health care professionals' perceptions of hospital-based cardiac rehabilitation in mainland China: an exploratory study. J Clin Nurs 2009, 18(24):3401-3408.

6. Leon AS, Franklin BA, Costa F, Balady GJ, Berra KA, Stewart KJ, Thompson PD, Williams MA, Lauer MS: Cardiac rehabilitation and secondary prevention of coronary heart disease: an American Heart Association scientific statement from the Council on Clinical Cardiology (Subcommittee on Exercise, Cardiac 
Rehabilitation, and Prevention) and the Council on Nutrition, Physical Activity, and Metabolism (Subcommittee on Physical Activity), in collaboration with the American association of Cardiovascular and Pulmonary Rehabilitation. Circulation 2005, 111(3):369-376.

7. Ades PA: Cardiac rehabilitation and secondary prevention of coronary heart disease. N Engl J Med 2001, 345(12):892-902.

8. Taylor RS, Brown A, Ebrahim S, Jolliffe J, Noorani H, Rees K, Skidmore B, Stone JA, Thompson DR, Oldridge N: Exercise-based rehabilitation for patients with coronary heart disease: systematic review and meta-analysis of randomized controlled trials. Am J Med 2004, 116(10):682-692.

9. Lavie CJ, Milani RV: Cardiac rehabilitation and exercise training in secondary coronary heart disease prevention. Prog Cardiovasc Dis 2011, 53(6):397-403.

10. Allen JK, Scott LB, Stewart KJ, Young DR: Disparities in women's referral to and enrollment in outpatient cardiac rehabilitation. $J$ Gen Intern Med 2004, 19(7):747-753.

11. Jackson L, Leclerc J, Erskine Y, Linden W: Getting the most out of cardiac rehabilitation: a review of referral and adherence predictors. Heart 2005, 91(1):10-14

12. Beswick AD, Rees K, Griebsch I, Taylor FC, Burke M, West RR, Victory J, Brown J, Taylor RS, Ebrahim S: Provision, uptake and cost of cardiac rehabilitation programmes: improving services to under-represented groups. Health Technol Assess 2004, 8(41):iii-iv. ix-x, 1-152.

13. Grace SL, Shanmugasegaram S, Gravely-Witte S, Brual J, Suskin N, Stewart DE: Barriers to cardiac rehabilitation: DOES AGE MAKE A DIFFERENCE? J Cardiopulm Rehabil Prev 2009, 29(3):183-187.

14. Altenhoener T, Leppin A, Grande G, Romppel M: Social inequality in patients' physical and psychological state and participation in rehabilitation after myocardial infarction in Germany. Int I Rehabil Res 2005, 28(3):251-257.

15. Witt BJ, Thomas RJ, Roger VL: Cardiac rehabilitation after myocardial infarction: a review to understand barriers to participation and potential solutions. Eura Medicophys 2005, 41(1):27-34.

16. Goto $\mathrm{Y}$, Itoh $\mathrm{H}$, Adachi $\mathrm{H}$, Ueshima $\mathrm{K}$, Nohara R: Use of exercise cardiac rehabilitation after acute myocardial infarction. Circ J 2003, 67(5):411-415.

17. Higgins RO, Murphy BM, Le Grande MR, Parkinson A, Worcester MU, Goble AJ: Expressed preferences for health education of patients after percutaneous coronary intervention. Eur J Cardiovasc Prev Rehabil 2005, 12(6):572-579.

18. Redfern J, Ellis E, Briffa T, Freedman SB: Modular prevention of heart disease following acute coronary syndrome (ACS). BMC Cardiovasc Disord 2006, 6:26.

19. Bagheri H, Memarian R, Alhani F: Evaluation of the effect of group counselling on post myocardial infarction patients: determined by an analysis of quality of life. J Clin Nurs 2007, 16(2):402-406.

20. Jolly K, Taylor R, Lip GY, Greenfield S, Raftery J, Mant J, Lane D, Jones M, Lee KW, Stevens A: The Birmingham Rehabilitation Uptake Maximisation Study (BRUM). Home-based compared with hospital-based cardiac rehabilitation in a multi-ethnic population: cost-effectiveness and patient adherence. Health Technol Assess 2007, 11(35):1-118.

21. Thompson DR, Man YC: Cardiac Rehabilitation in China. In Cardiovascular Prevention and Rehabilitation. London: Springer-Verlag; 2007:48-51.

22. Blum MR, Schmid JP, Eser P, Saner H: Long-term results of a 12-week comprehensive ambulatory cardiac rehabilitation program. J Cardiopulm Rehabil Prev 2013, 33(2):84-90.

23. Ware JE, Kosinske M, Gandek B: SF-36 Health Survey: Manual and Interpretation Guide. Lincoln, Rl: Quality Metric, Inc; 2003.

24. Kressin NR, Glickman ME, Peterson ED, Whittle J, Orner MB, Petersen LA: Functional status outcomes among white and African-American cardiac patients in an equal access system. Am Heart J 2007, 153(3):418-425

25. Fang K, Shia B, Ma S: Health insurance coverage and impact: a survey in three cities in China. PLoS One 2012, 7(6):e39157.

26. World Health Organization: The World Health Report; 2002:210.

27. Chan RH, Gordon NF, Chong A, Alter DA: Influence of socioeconomic status on lifestyle behavior modifications among survivors of acute myocardial infarction. Am J Cardiol 2008, 102(12):1583-1588.

28. Alter DA, Iron K, Austin PC, Naylor CD: Socioeconomic status, service patterns, and perceptions of care among survivors of acute myocardial infarction in Canada. JAMA 2004, 291(9):1100-1107.

29. Stewart DE, Abbey SE, Shnek ZM, Irvine J, Grace SL: Gender differences in health information needs and decisional preferences in patients recovering from an acute ischemic coronary event. Psychosom Med 2004, 66(1):42-48.
30. Oterhals $K$, Hanestad BR, Eide GE, Hanssen TA: The relationship between in-hospital information and patient satisfaction after acute myocardial infarction. Eur J Cardiovasc Nurs 2006, 5(4):303-310.

31. Oparil S: Pathophysiology of sudden coronary death in women. Implications for prevention. Circulation 1998, 97(21):2103-2105.

32. Mosca L, Ferris A, Fabunmi R, Robertson RM: Tracking women's awareness of heart disease: an American Heart Association national study. Circulation 2004, 109(5):573-579.

33. Mosca L, Mochari H, Christian A, Berra K, Taubert K, Mills T, Burdick KA, Simpson SL: National study of women's awareness, preventive action, and barriers to cardiovascular health. Circulation 2006, 113(4):525-534.

34. Rosenfeld AG, Lindauer A, Darney BG: Understanding treatment-seeking delay in women with acute myocardial infarction: descriptions of decision-making patterns. Am J Crit Care 2005, 14(4):285-293.

35. Smith J, Liles C: Information needs before hospital discharge of myocardial infarction patients: a comparative, descriptive study. J Clin Nurs 2007, 16(4):662-671.

36. Govil SR, Weidner G, Merritt-Worden T, Ornish D: Socioeconomic status and improvements in lifestyle, coronary risk factors, and quality of life: the Multisite Cardiac Lifestyle Intervention Program. Am J Public Health 2009, 99(7):1263-1270.

37. Bellman C, Hambraeus K, Lindback J, Lindahl B: Achievement of secondary preventive goals after acute myocardial infarction: a comparison between participants and nonparticipants in a routine patient education program in Sweden. J Cardiovasc Nurs 2009, 24(5):362-368

38. Steg PG, James SK, Atar D, Badano LP, Blomstrom-Lundqvist C, Borger MA, Di Mario C, Dickstein K, Ducrocq G, Fernandez-Aviles F, Gershlick AH, Giannuzzi P, Halvorsen S, Huber K, Juni P, Kastrati A, Knuuti J, Lenzen MJ, Mahaffey KW, Valgimigli M, van 't Hof A, Widimsky P, Zahger D: ESC guidelines for the management of acute myocardial infarction in patients presenting with ST-segment elevation. Eur Heart J 2012, 33(20):2569-2619.

39. Mak YM, Chan WK, Yue CS: Barriers to participation in a phase II cardiac rehabilitation programme. Hong Kong Med J 2005, 11(6):472-475.

40. Bethell HJ, Evans JA, Turner SC, Lewin RJ: The rise and fall of cardiac rehabilitation in the United Kingdom since 1998. J Public Health (Oxf) 2007, 29(1):57-61.

doi:10.1186/1471-2261-14-20

Cite this article as: Jin et al.: Obstacles and alternative options for cardiac rehabilitation in Nanjing, China: an exploratory study. BMC Cardiovascular Disorders 2014 14:20.

\section{Submit your next manuscript to BioMed Central and take full advantage of:}

- Convenient online submission

- Thorough peer review

- No space constraints or color figure charges

- Immediate publication on acceptance

- Inclusion in PubMed, CAS, Scopus and Google Scholar

- Research which is freely available for redistribution 